TITLE:

\title{
Conductive and photovoltaic properties of multilayered ultrathin films designed by layer-by-layer assembly of titanium oxides
}

\section{AUTHOR(S):}

Masuda, Kohji; Morita, Sumiko; Ohkita, Hideo; Benten, Hiroaki; Ito, Shinzaburo

\section{CITATION:}

Masuda, Kohji ...[et al]. Conductive and photovoltaic properties of multilayered ultrathin films designed by layer-by-layer assembly of titanium oxides. Thin Solid Films 2011, 519(8): 2493-2498

\section{ISSUE DATE:}

2011-02-01

URL:

http://hdl.handle.net/2433/138096

\section{RIGHT:}

(C) 2010 Elsevier B.V.; This is not the published version. Please cite only the published version.; この論文は出版社版でありません。引用の際に は出版社版をご確認ご利用ください。 


\section{Conductive and Photovoltaic Properties of Multilayered Ultrathin}

\section{Films Designed by Layer-by-Layer Assembly of Titanium Oxides}

Kohji Masuda, Sumiko Morita, Hideo Ohkita, ${ }^{\text {a) }}$ Hiroaki Benten, and Shinzaburo Ito Department of Polymer Chemistry, Graduate School of Engineering, Kyoto University,

Katsura, Nishikyo, Kyoto 615-8510, Japan

a) Author to whom correspondence should be addressed; FAX: +81-75-383-2617; electronic mail: ohkita@photo.polym.kyoto-u.ac.jp 


\section{Abstract}

Titania-based ultrathin films were fabricated by layer-by-layer (LbL) assembly of titanium (IV) bis(ammonium lactato) dihydroxide (TALH) and polyelectrolytes. The thickness of the titania monolayer in the LbL films was $4-5 \mathrm{~nm}$, which was consistent with the particle size of TALH in water. The conductivity and the electron mobility of the LbL films reached $10^{-8} \mathrm{~S}$ $\mathrm{cm}^{-1}$ and $10^{-5} \mathrm{~cm}^{2} \mathrm{~V}^{-1} \mathrm{~s}^{-1}$, respectively. These results suggest that there exist percolation paths for the electron transport in the LbL film. Furthermore, it is demonstrated that photovoltaic properties of the LbL film can serve as an effective electron-transporting and accepting layer.

Keywords

Layer-by-layer; Titanium oxide; Ultrathin film; Mobility; Photovoltaic cell 


\section{Introduction}

Titanium oxide, titania, has drawn attention because of its attractive optical and electronic characteristics. Various applications have been reported, such as optical filters, photocatalysts, and electronic devices [1-4]. Titania thin films have been fabricated not only by dry processes such as thermal deposition, sputtering, and chemical vapor deposition $[1,3,5]$ but also by the sol-gel method and other solution processes [6-8]. The solution processes are suitable for large-area and low-temperature fabrication, and are also applicable to the fabrication of organic-inorganic hybrid materials. Titanium alkoxides have been widely used as a precursor of titania. However, it is difficult to control the particle size precisely because of the rapid reaction of alkoxides in water. Thus, chemical additives are needed to control hydrolysis and condensation moderately [9]. Recently, bis(ammonium lactato)titanium dihydroxide (TALH) has been developed as a useful starting material of titania synthesis from an aqueous solution, because TALH is stable even in water at ambient temperature in contrast to titanium alkoxides. The hydrolysis and conversion of TALH into titania have been studied by Möckel and his co-workers in detail. They reported that titania converted from TALH is composed of monodisperse nanoparticles [10]. Furthermore, TALH serves as a negatively-charged ion in water, and is therefore applicable as an adsorbate in the layer-by-layer (LbL) deposition technique. Consequently, various nanostructures of titania such as core-shell nanoparticle [11], nanotube [12], and three-dimensional porous films $[13,14]$ have been reported so far.

The LbL deposition technique, which was developed by Decher, is based on electrostatic self-assembly of oppositely-charged species, and is now widely employed as a simple and versatile method for fabricating multilayered nanostructures [15-18]. As mentioned above, there are several reports on titania thin films developed by the LbL assembly of TALH. Caruso and his co-workers fabricated multilayered thin films of TALH 
and some polyelectrolytes by the LbL deposition technique [19]. Kim and his co-workers applied titania-based LbL thin films converted from TALH to transparent photocatalyst [20] and anti-reflection film [21]. On the other hand, titania has been widely used as an excellent electron-transporting material in photovoltaic cells. For example, titania nanoporous thin layers are employed as an electron-transporting material in dye-sensitized solar cells [22], and titania nanoparticles are blended as an electron-accepting material with a conjugated donor polymer in organic-inorganic hybrid solar cells [23]. Thus, titania-based LbL thin films are a promising material in multilayered photovoltaic cells. However, there are no reports on the conductive properties of titania-based LbL thin films.

In this paper, we fabricated titania-based LbL films from TALH, characterized the conductive properties, and demonstrate their application to photovoltaic cells. The dispersion state of TALH in water was analyzed by the dynamic light scattering measurement to discuss the deposition of TALH in the LbL assembly. The layered structure of the films was revealed by absorption and atomic force microscopy (AFM) measurements. The conductivity and electron mobility of the titania-based LbL films were evaluated quantitatively, suggesting that the titania-based LbL films can serve as an efficient electron-transporting material. Finally, photovoltaic properties were also demonstrated with multilayered solar cells designed by LbL assembly of TALH/poly(diallyldimethylammonium chloride) (PDDA) and poly(p-phenylenevinylene) (PPV)/poly(sodium 4-styrenesulfonate) (PSS). 


\section{Experimental}

\subsection{Materials}

For the LbL deposition, water was purified by deionization, distillation, and passing through a filtration system (Barnstead Nanopure II). An aqueous solution of titanium(IV) bis(ammonium lactato)dihydroxide (TALH; Aldrich, $50 \mathrm{wt} \%$ in water), which is a precursor of titania, was diluted to $5 \mathrm{wt} \%$ aqueous solution with water. An aqueous solution of poly(diallyldimethylammonium chloride) (PDDA; Aldrich, $20 \mathrm{wt} \%$ in water, $M_{\mathrm{w}}=$ 100000-200000 $\mathrm{g} \mathrm{mol}^{-1}$ ) was diluted to $1 \mathrm{mg} \mathrm{mL}^{-1}$ with $0.5 \mathrm{M} \mathrm{NaCl}$ aqueous solution. $\operatorname{Poly}(p$-xylene tetrahydrothiophenium chloride) (pre-PPV; Aldrich, $0.25 \mathrm{wt} \%$ in water), which is a precursor of poly ( $p$-phenylenevinylene) (PPV), was diluted to $1 \mathrm{mM}$ with water. Poly(sodium 4-styrenesulfonate) (PSS; Aldrich, $M_{\mathrm{w}}=70000 \mathrm{~g} \mathrm{~mol}^{-1}$ ) was dissolved at 10 $\mathrm{mM}$ with water. The pre-PPV solution was adjusted to $\mathrm{pH} 8-9$ with an $\mathrm{NaOH}$ aqueous solution. An aqueous solution of poly(3,4-ethylenedioxythiophene):poly(4-styrenesulfonate) (PEDOT:PSS; Aldrich, $1.3 \mathrm{wt} \%$ dispersion in water, conductive grade) was diluted to $10 \mathrm{mM}$ with water. These solutions were employed as polyelectrolyte solutions for the LbL deposition. An aqueous solution of anatase $\mathrm{TiO}_{2}$ nanoparticles with a diameter of $20 \mathrm{~nm}$ (Solaronix SA) was used for the fabrication of a nanoporous (np)- $\mathrm{TiO}_{2}$ film. Figure 1 shows the chemical structures of materials employed in this study.

\section{$---<<$ Figure $1>>---$}

\subsection{Fabrication of LbL films}

For UV-visible absorption and sheet-resistance measurements, quartz substrates were employed for the LbL deposition. These quartz substrates were cleaned by 
ultrasonication in toluene, acetone, and ethanol for 15 min each, then dried with a $\mathrm{N}_{2}$ flow, and treated with a $\mathrm{UV}-\mathrm{O}_{3}$ cleaner for $1 \mathrm{~h}$. The substrates were immersed in a cationic solution of PDDA for $15 \mathrm{~min}$, and rinsed in water twice for $2 \mathrm{~min}$ and $1 \mathrm{~min}$ each. Subsequently, they were immersed in an anionic solution of TALH for $15 \mathrm{~min}$, and rinsed in water for $3 \mathrm{~min}$. This cycle gives one bilayer of PDDA/TALH. The LbL films with $n$ bilayers of PDDA and TALH are abbreviated as (PDDA/TALH $)_{n}$. Note that PDDA/TALH LbL films were not dried after each immersion and rinsing. The PDDA/TALH LbL films were annealed in air to convert to $\mathrm{PDDA} / \mathrm{TiO}_{x} \mathrm{LbL}$ films. The LbL films were annealed first at $65{ }^{\circ} \mathrm{C}$ for $3 \mathrm{~h}$, and then at different temperatures from 70 to $220{ }^{\circ} \mathrm{C}$ for $24 \mathrm{~h}$. Similarly, pre-PPV/TALH LbL films were fabricated as described in Ref [24] and PPV/TiO LbL films were obtained by annealing at $220^{\circ} \mathrm{C}$ for $12 \mathrm{~h}$ under vacuum.

For the electron-mobility measurement, the indium-tin-oxide (ITO)-coated glass substrates (10 $\Omega$ square $^{-1}$ ) were employed for the LbL deposition. The substrates were cleaned and treated as described above. First, a buffer layer was prepared by the LbL deposition of PEDOT:PSS and PDDA as reported previously [25]. The thickness was 100 nm. Second, PDDA/TALH LbL films were fabricated on the buffer layer. Third, the LbL film was annealed as described above. Finally, Al was thermally deposited at $3.3 \times 10^{-4} \mathrm{~Pa}$ on top of the LbL film. The thickness of Al was $100 \mathrm{~nm}$. The layered structure is abbreviated as ITO $\left|(\mathrm{PEDOT}: \mathrm{PSS} / \mathrm{PDDA})_{20}\right|\left(\mathrm{PDDA} / \mathrm{TiO}_{x}\right)_{30} \mid \mathrm{Al}$. For comparison, np- $\mathrm{TiO}_{2}$ films were prepared by spin-coating followed by sintering at $150{ }^{\circ} \mathrm{C}$ in air for the sheet-resistance and electron-mobility measurements.

Photovoltaic cells with a planar heterojunction structure were fabricated by the LbL deposition technique. First, an acceptor layer was fabricated by the LbL assembly of TALH and PDDA on a cleaned ITO substrate as described above. Second, a donor layer was fabricated by the LbL assembly of pre-PPV and PSS as reported previously [24]. Third, a 
buffer layer of PEDOT:PSS was prepared by spincoating, followed by annealing at $100{ }^{\circ} \mathrm{C}$ for $24 \mathrm{~h}$ under vacuum. Finally, Au was thermally deposited. The thickness was $80 \mathrm{~nm}$ for the PEDOT:PSS layer and $100 \mathrm{~nm}$ for the Au electrode. The layered structure shown in Figure 2 is abbreviated as ITO $\left|\left(\mathrm{PDDA} / \mathrm{TiO}_{x}\right)_{5} / \mathrm{PDDA}\right|(\mathrm{PPV} / \mathrm{PSS})_{5} / \mathrm{PPV}|\mathrm{PEDOT}: \mathrm{PSS}| \mathrm{Au}$. For comparison, dense $\mathrm{TiO}_{2}\left(\mathrm{~d}-\mathrm{TiO}_{2}\right)$ films were prepared by the sol-gel method as reported previously [26].

$---<<$ Figure $2>>---$

\subsection{Measurements}

UV-visible absorption spectra of PDDA/TALH LbL films were measured before and after thermal annealing with a spectrophotometer (Hitachi, U-3500). The thickness and surface morphology of LbL films were measured with an atomic force microscope (Shimadzu, SPM-9500J) in contact mode. The particle size of TALH in water was evaluated by the dynamic light scattering measurement (DLS, Otsuka Electronics, ELS-Z2). The dynamic light scattering data were analyzed by the cumulant approach. The surface resistivity of LbL films and a np- $\mathrm{TiO}_{2}$ film was measured with a ring probe (Mitsubishi Chemical Analytech, UR-SS) connected to a digital electrometer (Advantest, R8252). The conductivity $\sigma$ is obtained from an inverse of the volume resistivity, which is given by the product of the surface resistivity and the film thickness. The current density-voltage $(J-V)$ characteristics of devices were measured with a DC voltage current source/monitor (Advantest, R6243). The electron mobility $\mu_{\mathrm{e}}$ was evaluated from the space-charge limited current, which is described by

$$
J=\frac{9}{8} \varepsilon_{0} \varepsilon_{\mathrm{r}} \mu_{\mathrm{e}} \frac{\left(V-V_{\mathrm{BI}}-V_{\mathrm{RS}}\right)^{2}}{d^{3}}
$$


where $\varepsilon_{0}$ is the permittivity of free space and $\varepsilon_{\mathrm{r}}$ is the relative dielectric constant. The effective $\varepsilon_{\mathrm{r}}$ of multicomponent films was estimated as the volume average of each component where $\varepsilon_{\mathrm{r}}\left(\mathrm{TiO}_{2}\right)$ and $\varepsilon_{\mathrm{r}}(\mathrm{PDDA})$ were set at 45 [27] and 1.8 [28], respectively. The value of $V_{\mathrm{RS}}$ is the voltage drop, which was given by the product of the series resistance $r_{\mathrm{s}}$, the device area, and the current density $J$. The built-in-voltage $V_{\mathrm{BI}}$ and $r_{\mathrm{s}}$ were treated as fitting parameters [29]. The $J-V$ characteristics of photovoltaic cells were measured with the DC voltage current source/monitor in the dark and under AM1.5G simulated solar illumination at $100 \mathrm{~mW} \mathrm{~cm}^{-2}$. The external quantum efficiency spectra were measured with the digital electrometer under monochromatic light illumination from a 500-W Xe lamp (Thermo Oriel, Model 66921) with a monochromator (Thermo Oriel, UV-visible Conerstone) and several optical cut-filters. All measurements were performed in air at room temperature. 


\section{Results and Discussion}

\subsection{TALH dispersion in water}

To clarify the deposition state of TALH in water, we measured the dynamic light scattering of an aqueous solution of TALH. The average particle size of TALH was estimated to be $5.7 \mathrm{~nm}$ with a narrow polydispersity index of $<0.01$ by the cumulant approach. The particle size remained the same even after several hours, suggesting that TALH is stable and does not form larger aggregates (oligomer or cluster) in water. These results are consistent with previous studies on $\mathrm{TiO}_{x}$ nanoparticles thermally converted from TALH at $<100{ }^{\circ} \mathrm{C}$, in which the size of the $\mathrm{TiO}_{x}$ nanoparticles was reported to be $3-5 \mathrm{~nm}[30,31]$. Thus, the stability of TALH against both hydrolysis and condensation to $\mathrm{TiO}_{x}$ is probably due to two bulky ligands in TALH, which is a chelate compound of a titanium ion coordinated by two ammonium lactates. We therefore conclude that TALH is dispersed in water as small aggregates with a diameter of $\sim 6 \mathrm{~nm}$, which can be deposited on a substrate as described later.

\subsection{Fabrication of $\mathrm{TiO}_{x}$ LbL films}

\section{$---<<$ Figure $3 \quad>>---$}

Figure 3 shows absorption spectra of PDDA/TALH LbL films on quartz substrates after various numbers of deposition cycles $(n=2,4,6,8)$. The broken and solid lines represent the absorption spectra before and after thermal annealing at $95{ }^{\circ} \mathrm{C}$ for $24 \mathrm{~h}$, respectively. The absorption at $\sim 250 \mathrm{~nm}$ is ascribed to $\mathrm{TiO}_{x}$ because PDDA has no absorption in this wavelength range and TALH has slightly different absorption. This absorption slightly increased after thermal annealing at $95^{\circ} \mathrm{C}$, as shown in the figure, but 
remained the same after additional thermal annealing at $220^{\circ} \mathrm{C}$ for $12 \mathrm{~h}$ (data not shown). These results indicate that TALH is partially converted into $\mathrm{TiO}_{x}$ because of drying during the LbL deposition, and completely converted into $\mathrm{TiO}_{x}$ after thermal annealing at $95{ }^{\circ} \mathrm{C}$. As shown in the inset of the figure, the absorbance at $250 \mathrm{~nm}$ increased in proportion to the number of deposition cycles. This linear growth indicates that TALH nanoparticles are quantitatively deposited in an LbL fashion. Figure 4 shows an AFM image of an LbL film of $\left(\mathrm{PDDA} / \mathrm{TiO}_{x}\right)_{6}$ on a quartz substrate. The LbL film was pinhole-free with a surface roughness of $<10 \mathrm{~nm}$, which is indicative of homogeneous deposition of TALH nanoparticles. The bright area on the right side is the surface of the LbL film and the dark area on the left side is the surface of quartz substrate where the LbL film was scratched out. From the difference in height between these levels, the total thickness of the LbL film was evaluated to be $32 \mathrm{~nm}$. As shown in the inset of Figure 4, the thickness of PDDA/TALH LbL films after thermal annealing increased in proportion to the number of deposition cycles. This is consistent with the linear growth in the absorbance mentioned above, suggesting again that TALH nanoparticles are quantitatively deposited in the LbL fashion. From the slope in the inset, the thickness of PDDA/ $\mathrm{TiO}_{x}$ bilayer was estimated to be $6.2 \pm 0.1 \mathrm{~nm}$.

\section{$---<<$ Figure $4 \quad>>---$}

To evaluate the monolayer thickness of $\mathrm{TiO}_{x}$ and PDDA in LbL films, we estimate the absorption coefficient of $\mathrm{TiO}_{x}$ layer as follows. First, $\mathrm{PPV} / \mathrm{TiO}_{x} \mathrm{LbL}$ films were prepared by thermal conversion of pre-PPV/TALH LbL films. The thickness of the PPV monolayer can be evaluated using the absorption coefficient $330000 \mathrm{~cm}^{-1}$ at $400 \mathrm{~nm}$ [32]. Next, the total thickness of PPV/TiO $\mathrm{LbL}$ films can be evaluated by the AFM measurement as described above. Thus, the thickness and the absorption coefficient of the $\mathrm{TiO}_{x}$ 
monolayer can be estimated from the difference. Figure 5 shows absorption spectra of $\mathrm{PPV} / \mathrm{TiO}_{x} \mathrm{LbL}$ films with various numbers of bilayers $(n=2,4,6)$ on quartz substrates. The absorption increased in proportion to the number of $\mathrm{PPV} / \mathrm{TiO}_{x}$ bilayers as shown by the solid line in the inset. From the slope of the solid line, the monolayer thickness of PPV in $\mathrm{PPV} / \mathrm{TiO}_{x} \mathrm{LbL}$ films was estimated to be $0.9 \pm 0.1 \mathrm{~nm}$. On the other hand, as shown by the broken line in the inset, the total thickness of $\mathrm{PPV} / \mathrm{TiO}_{x} \mathrm{LbL}$ films also increased in proportion to the number of $\mathrm{PPV} / \mathrm{TiO}_{x}$ bilayers. From the slope of the broken line, the bilayer thickness of PPV/TiO $\mathrm{LbL}$ films was estimated to be $5.7 \pm 0.1 \mathrm{~nm}$. Therefore, the monolayer thickness of $\mathrm{TiO}_{x}$ in $\mathrm{PPV} / \mathrm{TiO}_{x} \mathrm{LbL}$ films was estimated to be $4.8 \pm 0.2 \mathrm{~nm}$ and the absorption coefficient of the $\mathrm{TiO}_{x}$ layer was evaluated to be $300000 \mathrm{~cm}^{-1}$ at $250 \mathrm{~nm}$ [33]. On the basis of the absorption coefficient, the monolayer thickness of PDDA/TiO $\mathrm{LbL}$ films was estimated to be $2.2 \mathrm{~nm}$ for PDDA and $4 \mathrm{~nm}$ for $\mathrm{TiO}_{x}$ [33]. Interestingly, the monolayer thickness of $\mathrm{TiO}_{x}$ is $4-5 \mathrm{~nm}$ independently of counter polycations, which is consistent with that evaluated by other methods such as ellipsometry and quartz crystal microgravimetry [19]. Furthermore, it is in good agreement with the particle size of TALH in water. Thus, this finding also indicates that TALH nanoparticles are stably dispersed in water and quantitatively adsorbed on a substrate during the LbL deposition.

$---<<$ Figure $5 \quad>>---$

3.3 Conductive properties of $\mathrm{TiO}_{x}$ LbL films

$---<<$ Figure $6 \quad>>---$ 
To discuss the conductive properties of $\mathrm{PDDA} / \mathrm{TiO}_{x} \mathrm{LbL}$ films, we measured the conductivity $\sigma$ and the electron mobility $\mu_{\mathrm{e}}$. For comparison, np- $\mathrm{TiO}_{2}$ films were prepared by sintering of $\mathrm{TiO}_{2}$ nanoparticles at $150{ }^{\circ} \mathrm{C}$. Figure 6 shows the conductivity $\sigma$ of $\mathrm{PDDA} / \mathrm{TiO}_{x} \mathrm{LbL}$ films at room temperature after thermal annealing at different temperatures (open circles) and that of a np- $\mathrm{TiO}_{2}$ film (closed circle). The conductivity $\sigma$ of $\mathrm{PDDA} / \mathrm{TiO}_{x}$ LbL films was almost constant after thermal annealing in the range of $1-3 \times 10^{-9} \mathrm{~S} \mathrm{~cm}^{-1}$ below $150{ }^{\circ} \mathrm{C}$. It increased steeply after thermal annealing above $180{ }^{\circ} \mathrm{C}$ and reached $4 \times$ $10^{-8} \mathrm{~S} \mathrm{~cm}^{-1}$ at $220^{\circ} \mathrm{C}$, which is rather comparable to that of the np- $\mathrm{TiO}_{2}$ film $\left(2 \times 10^{-7} \mathrm{~S}\right.$ $\mathrm{cm}^{-1}$ ). These high conductivities $\sigma$ of PDDA/TiO ${ }_{x} \mathrm{LbL}$ films are indicative of semiconductors although the insulating polymer PDDA is involved in the film. This finding shows that there are conductive carriers and pathways in the LbL film due to percolation paths of $\mathrm{TiO}_{x}$ in the direction normal to the substrate. Higher conductivities $\sigma$ of PDDA/TiO $x$ LbL films annealed above $180{ }^{\circ} \mathrm{C}$ are probably attributed to decomposition of insulating PDDA at higher temperatures [34].

\section{$---<<$ Figure $7 \quad>>---$}

To prove the presence of the electron-transporting networks, we evaluated the electron mobility $\mu_{\mathrm{e}}$ of $\mathrm{PDDA} / \mathrm{TiO}_{x}$ LbL films. Figure 7 shows semi-logarithmic plots of $J-V$ characteristics of $\mathrm{PDDA} / \mathrm{TiO}_{x} \mathrm{LbL}$ films (circles) and a np- $\mathrm{TiO}_{2}$ film (squares) against $V-V_{\mathrm{BI}}-V_{\mathrm{RS}} . \quad$ The solid lines represent fitting curves for the $J-V$ characteristics by using eq. 1 . The dielectric constant $\varepsilon_{\mathrm{r}}$ of PDDA/TiO $\mathrm{PbL}_{x}$ films was estimated to be 30 considering the volume fraction of $\mathrm{TiO}_{x}$ in the $\mathrm{LbL}$ film (0.65). The dielectric constant $\varepsilon_{\mathrm{r}}$ of the np- $\mathrm{TiO}_{2}$ film was set to be 34 considering the volume fraction of $\mathrm{TiO}_{2}$ in the np- $\mathrm{TiO}_{2}$ film $(0.74)$ estimated from the assumption of the closest packing. As a result, the electron mobility $\mu_{\mathrm{e}}$ 
of the PDDA/TiO $x$ LbL film was evaluated to be $6 \times 10^{-5} \mathrm{~cm}^{2} \mathrm{~V}^{-1} \mathrm{~s}^{-1}$. This is comparable to $2 \times 10^{-4} \mathrm{~cm}^{2} \mathrm{~V}^{-1} \mathrm{~s}^{-1}$ evaluated for the $\mathrm{np}-\mathrm{TiO}_{2}$ film, suggesting higher conversion of $x$ in $\mathrm{TiO}_{x}$ even at a low temperature [35]. The high electron mobility shows that there are effective percolation paths of $\mathrm{TiO}_{x}$ in the film. This is mainly due to the high volume fraction of $\mathrm{TiO}_{x}$ as mentioned above and also due to the interpenetrating characteristics of LbL films as reported previously [25]. Table 1 summarizes $\sigma$ and $\mu_{\mathrm{e}}$ of the PDDA/TiO $\mathrm{PbL}_{x}$ films and the $\mathrm{np}-\mathrm{TiO}_{2}$ film. We therefore conclude that the $\mathrm{PDDA} / \mathrm{TiO}{ }_{x} \mathrm{LbL}$ films converted from TALH can serve as an efficient electron-transporting material.

\section{$---<<$ Table $1 \quad>>---$}

\subsection{Photovoltaic performance}

$---<<$ Figure $8 \quad>>--$

Finally, we demonstrate the application of $\mathrm{TiO}_{x} \mathrm{LbL}$ films to photovoltaic cells. Figure 8 shows $J-V$ characteristics of photovoltaic cells of ITO $\left|\left(\mathrm{PDDA} / \mathrm{TiO}_{x}\right)_{6}\right|(\mathrm{PPV} / \mathrm{PSS})_{5} / \mathrm{PPV}|\mathrm{PEDOT}: \mathrm{PSS}| \mathrm{Au}\left(\mathrm{TiO}_{x}\right.$ LbL-based cells, solid line $)$ and of ITO|d-TiO ${ }_{2}\left|(\mathrm{PPV} / \mathrm{PSS})_{5} / \mathrm{PPV}\right| \mathrm{PEDOT}: \mathrm{PSS} \mid \mathrm{Au}\left(\mathrm{d}-\mathrm{TiO}_{2}\right.$-based cells, broken line) under AM1.5G-simulated solar illumination at $100 \mathrm{~mW} \mathrm{~cm}^{-2}$. Device performance of $\mathrm{TiO}_{x}$ LbL-based cells was as follows: the short-circuit current density $J_{\mathrm{SC}}=0.14 \mathrm{~mA} \mathrm{~cm}^{-2}$, the open-circuit voltage $V_{\mathrm{OC}}=0.77 \mathrm{~V}$, the fillfactor $\mathrm{FF}=0.27$, and the power conversion efficiency $\mathrm{PCE}=0.03 \%$. On the other hand, device performance of $\mathrm{d}-\mathrm{TiO}_{2}$-based cells was as follows: $J_{\mathrm{SC}}=0.08 \mathrm{~mA} \mathrm{~cm}^{-2}, V_{\mathrm{OC}}=0.60 \mathrm{~V}, \mathrm{FF}=0.17$, and $\mathrm{PCE}=0.01 \%$. In other words, $\mathrm{TiO}_{x}$ LbL-based cells exhibited higher performances in all device parameters than those of 
d-TiO 2 -based cells. Figure 9 shows external quantum efficiency (EQE) of the two photovoltaic cells. Both cells should have the same absorption efficiency because of the

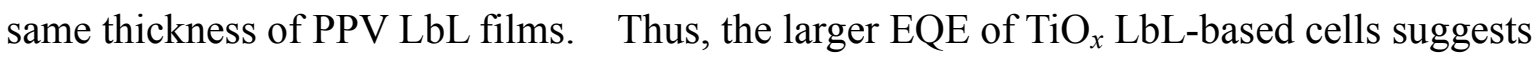
that the interfacial area would be larger in $\mathrm{TiO}_{x} \mathrm{LbL}$-based cells than in $\mathrm{d}-\mathrm{TiO}_{2}$-based cells. As shown in Figure 4, the PDDA/TiO ${ }_{x} \mathrm{LbL}$ film was pin-hole free but had a surface roughness of $<10 \mathrm{~nm}$. This is probably due to $\mathrm{TiO}_{x}$ nanoparticles being as small as $6 \mathrm{~nm}$. Considering the particle size of $\mathrm{TiO}_{x}$, the surface area of $\mathrm{TiO}_{x} \mathrm{LbL}$ films is roughly estimated to be 1.5 times compared to that of $\mathrm{d}-\mathrm{TiO}_{2}$ films. We therefore attribute the increase in $J_{\mathrm{SC}}$ to the larger interface area in $\mathrm{TiO}_{x} \mathrm{LbL}$ films. The interpenetration between $\mathrm{TiO}_{x}$ and $\mathrm{PPV}$ layers at the interface also contributes to the increase in $J_{\mathrm{SC}}$. Thus, we conclude that the $\mathrm{TiO}_{x} \mathrm{LbL}$ film can be employed as an effective electron-transporting layer and an acceptor layer in photovoltaic cells.

$---<<$ Figure $9>>--$

\section{Conclusions}

We fabricated titania-based ultrathin films by the LbL assembly of TALH and PDDA or PPV where TALH was completely converted into $\mathrm{TiO}_{x}$ in the $\mathrm{LbL}$ films by thermal annealing at $95{ }^{\circ} \mathrm{C}$ for $24 \mathrm{~h}$. The thickness of ultrathin films was precisely controlled by the LbL deposition on a scale of nanometers. From the absorption and AFM measurements, the monolayer thickness of each layer was estimated to be $2.2 \mathrm{~nm}$ for PDDA and $4 \mathrm{~nm}$ for $\mathrm{TiO}_{x}$ in $\mathrm{PDDA} / \mathrm{TiO}_{x} \mathrm{LbL}$ films and $0.9 \mathrm{~nm}$ for PPV and $4.8 \mathrm{~nm}$ for $\mathrm{TiO}_{x}$ in $\mathrm{PPV} / \mathrm{TiO}_{x} \mathrm{LbL}_{\text {films. }}$ Consequently, the volume fraction was as high as $\sim 65 \%$ for $\mathrm{PDDA} / \mathrm{TiO}_{x} \mathrm{LbL}$ films and $\sim 85 \%$ for $\mathrm{PPV} / \mathrm{TiO}_{x} \mathrm{LbL}$ films. The monolayer thickness of $\mathrm{TiO}_{x}(4-5 \mathrm{~nm})$ is consistent with the particle size $(\sim 6 \mathrm{~nm})$ of TALH in water evaluated by the dynamic light scattering 
measurement. We therefore conclude that TALH is stably dispersed in water as monodisperse nanoparticles with a diameter of $\sim 6 \mathrm{~nm}$ and quantitatively adsorbed on a substrate during the LbL deposition. The conductivity $\sigma$ of $\mathrm{PDDA}^{\mathrm{TiO}} \mathrm{LbL}_{x}$ films was $1-3$ $\times 10^{-9} \mathrm{~S} \mathrm{~cm}^{-1}$ at annealing temperatures below $150{ }^{\circ} \mathrm{C}$, increased steeply above $180^{\circ} \mathrm{C}$, and then reached $4 \times 10^{-8} \mathrm{~S} \mathrm{~cm}^{-1}$ at $220^{\circ} \mathrm{C}$, which is indicative of semiconductors. The electron mobility $\mu_{\mathrm{e}}$ of PDDA/TiO $x$ LbL film was evaluated to be $6 \times 10^{-5} \mathrm{~cm}^{2} \mathrm{~V}^{-1} \mathrm{~s}^{-1}$, which is comparable to that of a np- $\mathrm{TiO}_{2}$ film. We therefore conclude that there exist effective percolation paths of $\mathrm{TiO}_{x}$ in the direction normal to the substrate in the LbL films. This is mainly due to the high volume fraction of $\mathrm{TiO}_{x}$ in the film. Furthermore, we demonstrated planar heterojunction photovoltaic cells with PPV-based LbL films as an electron-donating layer and $\mathrm{TiO}_{x}$-based $\mathrm{LbL}$ films as an electron-accepting layer. The photovoltaic cell exhibited a higher device performance than the reference cell with a d- $\mathrm{TiO}_{2}$ layer because of the larger interface area due to $\mathrm{TiO}_{x}$ nanoparticles. We thus conclude that the $\mathrm{TiO}_{x}$-based LbL films can serve not only as an electron-transporting but also as an electron-accepting material.

\section{Acknowledgments}

This work was partly supported by the Global COE program (International Center for Integrated Research and Advanced Education in Materials Science) and by the Integrative Industry-Academia Partnership (IIAP) project including Kyoto University, Hitachi, Ltd., and Mitsubishi Chemical Corporation. 


\section{References and note}

[1] X. Chen, S.S. Mao, Chem. Rev. 107 (2007) 2891.

[2] G.K. Mor, O.K. Varghese, M. Paulose, K. Shankar, C.A. Grimes, Sol. Energy Mater. Sol.

Cells 90 (2006) 2011.

[3] L. Martinu, D. Poitras, J. Vac. Sci. Technol. A 18 (2000) 2619.

[4] K. Kalyanasundaram, M. Grätzel, Coord. Chem. Rev. 77 (1998) 347.

[5] J.-M. Wu, H.C. Shih, W.-T. Wu, Y.-K. Tseng, I-C. Chen, J. Cryst. Growth 281 (2005) 384.

[6] C.-C. Wang, J.Y. Ying, Chem. Mater. 11 (1999) 3113.

[7] T. Watanabe, S. Fukayama, M. Miyauchi, A. Fujishima, K. Hashimoto, J. Sol-Gel Sci.

Technol. 19 (2000) 71.

[8] Y. Li, T. Kunitake, S. Fujikawa, J. Phys. Chem. B 110 (2006) 13000.

[9] U. Schubert, J. Mater. Chem. 15 (2005) 3701.

[10] H. Möckel, M. Giersig, F. Willig, J. Mater. Chem. 9 (1999) 3051.

[11] K.S. Mayya, D.I. Gittins, F. Caruso, Chem. Mater. 13 (2001) 3833.

[12] A. Yu, G.Q. M. Lu, J. Drennan, I.R. Gentle, Adv. Funct. Mater. 17 (2007) 2600.

[13] Z. Wang, N.S. Ergang, M.A. Al-Daous, A. Stein, Chem. Mater. 17 (2005) 6805.

[14] C. Dionigi, P. Greco, G. Ruani, M. Cavallini, F. Borgatti, F. Biscarini, Chem. Mater. 20 (2008) 7130.

[15] G. Decher, Science 277 (1997) 1232. 
[16] K. Ariga, J.P. Hill, Q. Ji, Phys. Chem. Chem. Phys. 9 (2007) 2319.

[17] P.T. Hammond, Adv. Mater. 16 (2004) 1271.

[18] F. Caruso, Adv. Mater. 13 (2001) 11.

[19] X. Shi, T. Cassagneau, F. Caruso, Langmuir 18 (2002) 904.

[20] J.-H. Kim, S. Fujita, S. Shiratori, Thin Solid Films 499 (2006) 83.

[21] J.-H. Kim, S. Fujita, S. Shiratori, Colloids Surf. A 284 (2006) 290.

[22] B. O’Regan, M. Grätzel, Nature 353 (1991) 737.

[23] P. Ravirajan, S.A. Haque, J.R. Durrant, D.D.C. Bradley, J. Nelson, Adv. Funct. Mater. 15 (2005) 609

[24] M. Ogawa, N. Kudo, H. Ohkita, S. Ito, H. Benten, Appl. Phys. Lett. 90 (2007) 223107.

[25] D. Wakizaka, T. Fushimi, H. Ohkita, S. Ito, Polymer 45 (2004) 8561.

[26] C.D. Grant, A.M. Schwartzberg, G.P. Smestad, J. Kowalik, L.M. Tolbert, J.Z. Zhang, Synth. Met. 132 (2003) 197.

[27] R. O’Hayre, M. Nanu, J. Schoonman, A. Goossens, J. Phys. Chem. C 111 (2007) 4809.

[28] R. Asmatulu, B. Geist, W.B. Spillman Jr, R.O. Claus, Smart Mater. Struct. 14 (2005) 1493.

[29] S.M. Tuladhar, D. Poplavskyy, S.A. Choulis, J.R. Durrant, D.D.C. Bradley, J. Nelson, Adv. Funct. Mater. 15 (2005) 1171.

[30] A. Hanprasopwattana, T. Rieker, A.G. Sault, A.K. Datye, Catal. Lett. 45 (1997) 165. 
[31] N. Laugel, J. Hemmerlé, N. Ladhari, Y. Arntz, E. Gonthier, Y. Haikel, J.-C. Voegel, P.

Schaaf, V. Ball, J. Colloid Interface Sci. 324 (2008) 127.

[32] H. Benten, M. Ogawa, H. Ohkita, S. Ito, Adv. Funct. Mater. 18 (2008) 1563.

[33] Considering the scattering, the absorption coefficient of the $\mathrm{TiO}_{x}$ layer would be slightly

larger. When the scattering is neglected, the monolayer thickness is slightly underestimated for PDDA and overestimated for $\mathrm{TiO}_{x}$. However, the variation of the monolayer thickness would be less than $1 \mathrm{~nm}$. Thus, in either case, the discussion remains the same.

[34] P.C. Huang, K.-H. Reichert, Angew. Makromol. Chem. 165 (1989) 1.

[35] K. Katagiri, T. Suzuki, H. Muto, M. Sakai, A. Matsuda, Colloid Surf. A 321 (2008) 233. 


\section{Figure Captions}

Figure. 1. Chemical structures in this study.

Figure. 2. Layered structures and energy diagrams of photovoltaic cells with $\mathrm{TiO}_{x} \mathrm{LbL}$ films.

Figure 3. Absorption spectra of PDDA/TALH LbL films (2, 4, 6, 8 deposition cycles) before (broken lines) and after (solid lines) thermal annealing. The inset shows the absorbance at $250 \mathrm{~nm}$ plotted against the number of deposition cycles.

Figure 4. AFM image of a $\mathrm{PDDA} / \mathrm{TiO}_{x} \mathrm{LbL}$ film with 6 bilayers (after annealing). The left side of the film was scratched out. The inset shows the thickness of PDDA/TiO $x$ LbL films plotted against the number of bilayers.

Figure 5. Absorption spectra of $\mathrm{PPV} / \mathrm{TiO}_{x} \mathrm{LbL}$ films (2, 4, 6 bilayers). The inset shows the absorbance at $400 \mathrm{~nm}$ (circles, solid line) and the thickness (triangles, broken line) plotted against the number of bilayers.

Figure 6. Plots of the conductivity of $\mathrm{PDDA} / \mathrm{TiO}_{x} \mathrm{LbL}$ films (open circles) and a np- $\mathrm{TiO}_{2}$ film (closed circle) against annealing temperatures. The thickness of the $\mathrm{PDDA} / \mathrm{TiO}_{x} \mathrm{LbL}$ film and the np- $\mathrm{TiO}_{2}$ film were $130 \mathrm{~nm}$ and $160 \mathrm{~nm}$, respectively.

Figure 7. Double-logarithmic plots of the $J-V$ characteristics of $\mathrm{PDDA} / \mathrm{TiO}_{x} \mathrm{LbL}$ (circles) films and the np- $\mathrm{TiO}_{2}$ film (squares) against $V-V_{\mathrm{BI}}-V_{\mathrm{RS}}$. The solid lines represent fitting curves using the eq. 1 with the following parameters: the PDDA/ $\mathrm{TiO}_{x} \mathrm{LbL}$ films; film thickness $d=180 \mathrm{~nm}, V_{\mathrm{BI}}=0 \mathrm{~V}, r_{\mathrm{s}}=10 \Omega, \mu_{\mathrm{e}}=7 \times 10^{-5} \mathrm{~cm}^{2} \mathrm{~V}^{-1} \mathrm{~s}^{-1}$ and the np-TiO 2 film; $d=160 \mathrm{~nm}, V_{\mathrm{BI}}=0 \mathrm{~V}, r_{\mathrm{s}}=10 \Omega, \mu_{\mathrm{e}}=2 \times 10^{-4} \mathrm{~cm}^{2} \mathrm{~V}^{-1} \mathrm{~s}^{-1}$ at $\varepsilon_{\mathrm{r}}=$ 24.

Figure 8. $J-V$ characteristics of photovoltaic cells with layered structures of ITO|(PDDA/TALH) 6 (40 nm)|(PPV/PSS) $/$ PPV (12 nm)|PEDOT:PSS (80 nm)|Au 
(solid line) and $\mathrm{ITO}\left|\mathrm{d}-\mathrm{TiO}_{2}(60 \mathrm{~nm})\right|(\mathrm{PPV} / \mathrm{PSS})_{5} / \mathrm{PPV}(12 \mathrm{~nm}) \mid \mathrm{PEDOT}: \mathrm{PSS}$ (80 $\mathrm{nm}) \mid \mathrm{Au}$ (broken line).

Figure 9. EQE spectra of photovoltaic cells of ITO|(PDDA/TALH) $6(40$ nm)|(PPV/PSS) 5 PPV (12 nm)|PEDOT:PSS (80 nm)|Au (open circles) and ITO $\left|\mathrm{d}-\mathrm{TiO}_{2}(60 \mathrm{~nm})\right|(\mathrm{PPV} / \mathrm{PSS})_{5} / \mathrm{PPV}(12 \mathrm{~nm})|\mathrm{PEDOT}: \mathrm{PSS}(80 \mathrm{~nm})| \mathrm{Au}(\mathrm{closed}$ circles). The solid line denotes the absorption spectrum of a PPV LbL film annealed at $100^{\circ} \mathrm{C} 2 \mathrm{~h}$. 